\title{
Knowledge and Practice Behaviors Regarding Urinary Incontinence Among Korean Healthcare Providers in Long-term Care Hospitals
}

\author{
Yeonsoo Jang ${ }^{1}$, Bo Eun Kwon², Hyung Suk Kim³ ${ }^{3}$ Young Ju Lee ${ }^{3}$, Sangrim Lee ${ }^{4}$, Su Jin Kim5, Chang Wook Jeong³, \\ Khae Hawn Kim ${ }^{6}$ \\ ${ }^{1}$ Mo-Im Kim Nursing Research Institute, Yonsei University College of Nursing, Seoul, Korea \\ ${ }^{2}$ Seoul Women's College of Nursing, Seoul, Korea \\ ${ }^{3}$ Department of Urology, Seoul National University College of Medicine, Seoul, Korea \\ ${ }^{4}$ Seoul National University College of Nursing, Seoul, Korea \\ ${ }^{5}$ Department of Urology, Seoul St. Mary's Hospital, College of Medicine, The Catholic University of Korea, Seoul, Korea \\ ${ }^{6}$ Department of Urology, Gachon University Gil Medical Center, Gachon University School of Medicine, Incheon, Korea
}

\begin{abstract}
Purpose: The purpose of this study was to assess the current management status of patients with urological issues and to examine the level of knowledge and practice behaviors regarding urinary incontinence (UI) among Korean healthcare providers in long-term care hospitals.

Methods: This study used a cross-sectional descriptive design with a written questionnaire to assess knowledge and practice behaviors of 756 healthcare providers in 11 long-term care hospitals in Korean metropolitan areas.

Results: A total $42.6 \%$ of participants reported that more than $50 \%$ of patients had urologic issues, and that $68.1 \%$ of patients were regularly sent to urologists; no participants reported an on-site urologist in their facility. Participants identified collaboration with other hospitals and regular consultations by urologists as important factors in improving urologic care. Although the overall UI knowledge score was upper intermediate, a knowledge deficit was found for risk factors of UI. The knowledge level of physicians was significantly higher than that of other healthcare providers. Practice behaviors of nurses seemed to be better than those of other healthcare providers.

Conclusions: Systematic collaboration between healthcare providers and urologic specialists, enhancing staff competence, and patient-tailored intervention should be recommended to improve quality of care for patients with urologic issues in longterm care hospitals.
\end{abstract}

Keywords: Urinary Incontinence; Knowledge; Professional Practice; Health Personnel; Long-Term Care

- Grant Support: This study was supported by the Research Foundation for Korean Urological Association in 2014 (FKUA-2014-001).

- Research Ethics: This study was approved by the Institutional Review Board of Seoul National University Hospital (IRB No.: E-1410-080-618).

- Conflict of Interest: No potential conflict of interest relevant to this article was reported.

Corresponding author: Chang Wook Jeong (iD http://orcid.org/0000-0002-2200-5019 Department of Urology, Seoul National University College of Medicine, 103 Daehak-ro, Jongno-gu, Seoul 03080, Korea

E-mail:drboss@gmail.com / Tel: +82-2-2072-3899/ Fax: +82-2-742-4665

Co-corresponding author: Khae Hawn Kim id http://orcid.org/0000-0002-7045-8004 Department of Urology, Gachon University Gil Medical Center, Gachon University School of Medicine, 21 Namdong-daero 774 beon-gil, Namdong-gu, Incheon 21565, Korea

E-mail: kimcho99@gilhospital.com / Tel: +82-32-460-3331 / Fax: +82-32-460-8340

-Yeonsoo Jang (iD http:// orcid.org/0000-0002-1898-025X

Submitted: December 4, 2015 / Accepted after revision: December 11, 2015 


\section{INTRODUCTION}

Urinary incontinence (UI) can be defined as a complaint of involuntary leakage of urine and is a highly prevalent condition [1]. The prevalence of UI was reportedly $30 \%$ among women aged 30-60 years in Europe [2], and about 40\% among women aged 30 years and over in the United States [3]. In Korea, the prevalence of UI has been reported as $21 \%$ in individuals aged $20-40$ years, $40 \%-60 \%$ in those aged $50-70$ years, $64.7 \%$ in those in nursing homes [4], and $48.1 \%$ in individuals aged 65 and over in long-term care hospitals [5].

UI is associated with adverse effects on the quality of life even though it is not a life-threatening disease [6,7]. Medical staff competence, knowledge, and practice skills are associated with both general and urologic quality of care. However, the level of confidence in providing urologic care may differ among healthcare providers. Previous studies reported that the level of UI knowledge and attitudes of nurses were better than those of nursing assistants in nursing homes, and that this difference might be associated with the quality of care. However, a knowledge deficit was found in both of these healthcare provider groups $[8,9]$. According to one study, some treatments are provided without evidence of benefit, even when physicians other than urologists feel confident in the management of UI [10]. Therefore, education of medical staff is important to improve the quality of care for patients with UI.

A previous study assessed UI management in a Korean longterm care hospital, and reported that patients received standardized interventions rather than personalized care based on a patient's needs and characteristics [5]. However, there are no data concerning UI knowledge and practice behaviors among healthcare providers in long-term care hospitals in Korea.

The purpose of this study was to assess the current management status of patients with urological issues and to examine the level of knowledge and practice behaviors regarding UI among Korean healthcare providers in long-term care hospitals.

\section{MATERIALS AND METHODS}

\section{Design and Study Subjects}

This study used a cross-sectional descriptive design with a written questionnaire to assess knowledge and practice behaviors. A total 756 healthcare providers in 11 long-term care hospitals in Korean metropolitan areas were studied. Data collection was conducted from January to March 2015 with approval from the
Institutional Review Board of Seoul National University Hospital (IRB No.: E-1410-080-618).

\section{Measurements}

This study assessed the management of patients with UI and knowledge and practice behaviors about UI among healthcare providers. Management status was developed by the research team and it determined from the number of patients with urologic issues, the need for an urologist for UI management, priorities to improve urologic care, and information about healthcare providers for patients with UI. To identify perceived importance for improving urologic care, participants were asked the level of importance (range, 1-4; 1, least important; 4, most important) among three items; collaboration with other hospitals, regular consult by urologist, and residence of urologist. We also assessed the satisfaction for their current management regarding urologic care (1, very insufficient; 2 , insufficient; 3 , sufficient; 4 , very sufficient).

To assess knowledge and practice behaviors regarding UI among healthcare providers, a questionnaire was revised by a research team based on knowledge and practice instruments [8]. This consisted of 18 items related to knowledge and five related to practice behaviors regarding UI among healthcare providers. Each item was answered "yes" or "no".

\section{Data Analysis}

All statistical analyses in this study were performed using IBM SPSS Statistics ver. 22.0 (IBM Co., Armonk, NY, USA). Descriptive statistics were used for demographic characteristics, management status, knowledge, and attitudes. Differences in knowledge and attitudes by type of healthcare provider were determined using analysis of variance and chi-square tests. Statistical significance was preset at an alpha level of 0.05 .

\section{RESULTS}

Demographic Characteristics and Management Status of UI The demographic characteristics and UI management status of participants in this study are presented in Table 1 . The mean age was 39.9 years (standard deviation [SD], 8.4; range, 22-61 years), and $90.7 \%$ of participants were women. Among participants, $57.4 \%$ were nurses and $28.2 \%$ were certified caregivers. The mean length of work experience in a long-term care hospital was 51.5 months (SD, 35.0; range, 1-168 months) in this study sample. 
Table 1. Demographic characteristics and management status of urinary incontinence $(n=756)$

\begin{tabular}{|c|c|}
\hline Variable & Value \\
\hline Age (yr) & $39.9 \pm 8.4(22-61)$ \\
\hline $\begin{array}{l}\text { Sex } \\
\text { Men } \\
\text { Women }\end{array}$ & $\begin{array}{c}70(9.3) \\
686(90.7)\end{array}$ \\
\hline $\begin{array}{l}\text { Occupation } \\
\text { Physician } \\
\text { Nurse } \\
\text { Certified caregiver } \\
\text { Physical therapist }\end{array}$ & $\begin{array}{c}61(8.0) \\
434(57.4) \\
213(28.2) \\
48(6.3)\end{array}$ \\
\hline Length of work experiences (mo) & $51.5 \pm 35.0(1-168)$ \\
\hline $\begin{array}{l}\text { No. of patients with urologic problems } \\
\geq 5 \text { of } 10 \\
3-4 \text { of } 10 \\
1-2 \text { of } 10 \\
<1 \text { of } 10\end{array}$ & $\begin{array}{c}322(42.6) \\
279(36.9) \\
88(11.6) \\
67(8.9)\end{array}$ \\
\hline $\begin{array}{l}\text { Management pattern for patients with u } \\
\text { problems } \\
\text { Residence of urologist } \\
\text { Regular check-up by visiting urologist } \\
\text { Patient's regular visit to urologist } \\
\text { Refer to urologist in patents occurred } \\
\text { None }\end{array}$ & $\begin{array}{c}0(0) \\
7(0.9) \\
223(29.5) \\
515(68.1) \\
11(1.5)\end{array}$ \\
\hline $\begin{array}{l}\text { Effectiveness of current urologic manage } \\
\text { Less effective } \\
\text { Moderate } \\
\text { Effective } \\
\text { Very effective }\end{array}$ & $\begin{array}{c}21(2.8) \\
346(45.8) \\
382(50.5) \\
7(0.9)\end{array}$ \\
\hline $\begin{array}{l}\text { Need of management by urologist } \\
\text { No need } \\
\text { Moderate } \\
\text { Needed } \\
\text { Much-needed }\end{array}$ & $\begin{array}{c}34(4.5) \\
302(39.9) \\
404(53.4) \\
16(2.1)\end{array}$ \\
\hline $\begin{array}{l}\text { Care provider for urologic management } \\
\text { Physician only } \\
\text { Physician and nurse } \\
\text { Nurse only } \\
\text { Family only } \\
\text { Nurse and family } \\
\text { Physician and family } \\
\text { Certified caregiver only }\end{array}$ & $\begin{array}{c}340(45.0) \\
277(36.7) \\
114(15.1) \\
8(1.1) \\
8(1.1) \\
6(0.8) \\
3(0.4)\end{array}$ \\
\hline
\end{tabular}

Values are presented as mean \pm standard deviation (range) or number (\%).

A total $42.6 \%$ of participants reported that the prevalence of patients with urologic issues was greater than $50 \%$. Of those patients with urologic problems, $68.1 \%$ were regularly sent to an urologist, and no participants reported an on-site urologist in their hospital.

\section{Collaboration with other hospitals}

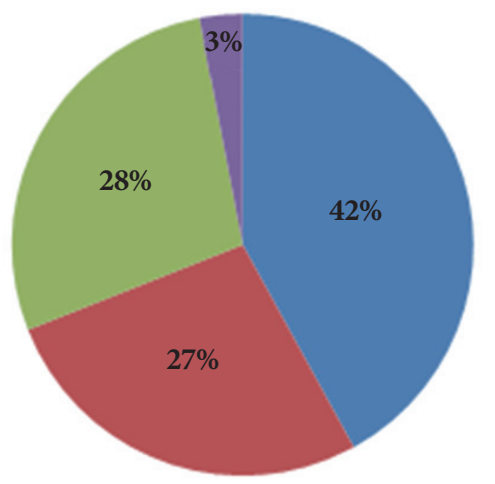

Importance

- Most

- Moderate

Less

- Least

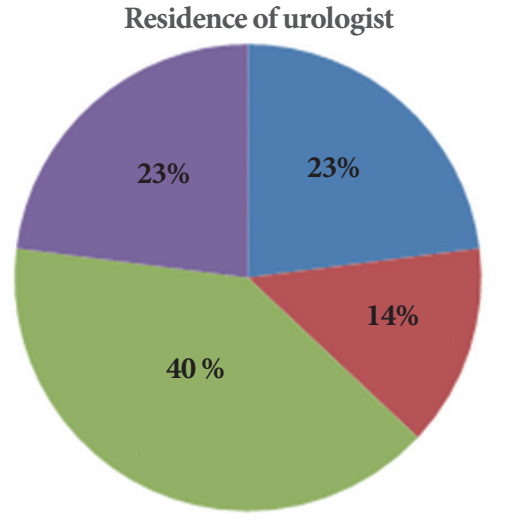

Importance

- Most

- Moderate

믈

a Least

\section{B}

A

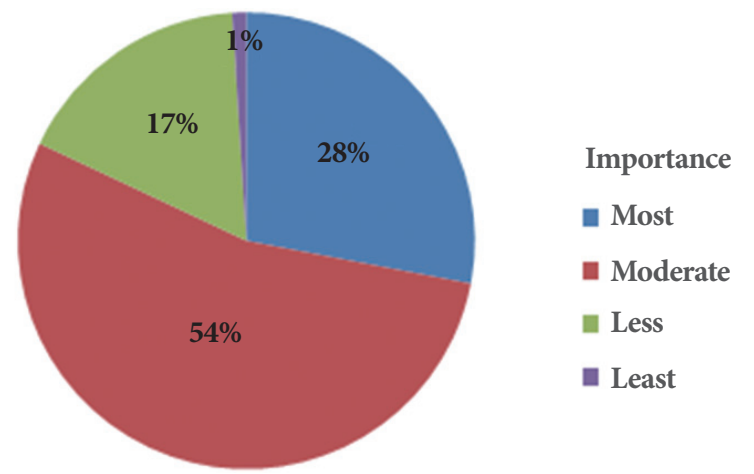

Fig. 1. Perceived importance for improving urologic care (\%). The participant responded to the level of importance among four items (A, collaboration with other hospitals; B, residence of urologist; $\mathrm{C}$, regular consult by urologist).

\section{Perceived importance for improving urologic care}

To improve urologic care, $42 \%$ of participants reported the item of "collaboration with other hospitals" was the most important, while 3\% of them answered it was the least important in this study. Twenty eight percent of participants responded the item of "regular consult by urologist" as the most important item to improve urologic care. In the item of "residence of urologist", 
Table 2. Knowledge and practice behaviors of urinary incontinence $(n=756)$

\begin{tabular}{|c|c|}
\hline Variable & No. $(\%)$ \\
\hline \multicolumn{2}{|l|}{ Knowledge } \\
\hline 1. On admission to hospitals, more women are incontinent than men. & $721(95.4)$ \\
\hline 2. Having a stroke may lead to urinary incontinence. & $699(92.5)$ \\
\hline 3. Demented residents are more often urinary incontinent than nondemented residents. & $689(91.1)$ \\
\hline 4. Toilet training can improve incontinence in older people requiring care. & $679(89.8)$ \\
\hline 5. Older people who have Parkinson are also often incontinence. & $676(89.4)$ \\
\hline 6. Stress incontinence is caused by psychological problems. & $666(88.1)$ \\
\hline 7. A bladder infection can cause urinary incontinence. & $655(86.6)$ \\
\hline 8. Older men may suffer from urinary incontinence after a prostate surgery. & $654(86.5)$ \\
\hline 9. Urinary incontinence can occur more often in sneezing, coughing or walking. & $638(84.4)$ \\
\hline 10. Some antihypertensive or sleep medications can cause urinary incontinence. & $634(83.8)$ \\
\hline 11. Urinary incontinence improves in most residents with suitable treatment. & $619(81.9)$ \\
\hline 12. Diabetes can cause urinary incontinence. & $601(79.5)$ \\
\hline 13. Certain medications can treat urinary incontinence. & $589(77.9)$ \\
\hline 14. Mobility-limited residents are equally often urinary incontinent as mobile residents. & $547(72.4)$ \\
\hline 15. Urinary incontinence is a more part of aging (over 65 years). & $542(71.7)$ \\
\hline 16. When awake, most people need to empty the bladder every $2-4$ hours. & $485(64.2)$ \\
\hline 17. More than $80 \%$ of all residents in nursing homes suffer from urinary incontinence. & $472(62.4)$ \\
\hline 18. More residents suffer from urinary incontinence after being in a nursing home for a year than at admission. & $416(55.0)$ \\
\hline \multicolumn{2}{|l|}{ Practice behaviors } \\
\hline 1. If incontinent residents express a wish to go to the toilet, I help them if necessary. & $724(95.8)$ \\
\hline 2. If a resident become incontinent, I inform the doctor. & $709(93.8)$ \\
\hline 3. On admission and if the health status changes, I ask the resident how long he/she has been incontinent. & $625(82.7)$ \\
\hline 4. I note in the documentation the times at which the incontinent residents drink. & $516(68.3)$ \\
\hline 5. I know whether the residents drink beverages with caffeine or other beverages with diuretic effects (e.g., coffee, coke, etc.). & $465(61.5)$ \\
\hline
\end{tabular}

Table 3. Differences of urinary incontinence knowledge by healthcare providers $(n=756)$

\begin{tabular}{llccc}
\hline Healthcare providers & Mean \pm SD & F & P-value & Scheffe \\
\hline Physician $^{\mathrm{a}}$ & $15.02 \pm 1.63$ & & & \\
Nurse $^{\mathrm{b}}$ & $14.14 \pm 2.14$ & 16.973 & $<0.001$ & $\mathrm{a}>\mathrm{b}, \mathrm{c}>\mathrm{d}$ \\
Certified caregivers $^{\mathrm{c}}$ & $14.03 \pm 1.94$ & & & \\
Physical therapist $^{\mathrm{d}}$ & $12.19 \pm 2.72$ & & \\
\hline
\end{tabular}

$\mathrm{SD}$, standard deviation.

$23 \%$ of participants answered it was the least important even though $23 \%$ of them reported it was the most important item for improving urologic care (Fig. 1). In the satisfaction for their current management of urologic care, $73 \%$ of participants were very insufficient. $15 \%$ of them were insufficient, and $5 \%$ of them were sufficient. Only $7 \%$ of them responded that the current management was very sufficient.

\section{Knowledge and Practice Behaviors}

The mean score for UI knowledge was 14.6 (SD, 2.15; range, 4-18) which is an $81 \%$ correct rate. The item with the highest correct rate was: "On admission to hospitals, more women are incontinent than men," which $95.4 \%$ of participants answered correctly. The item with the lowest correct rate was: "More residents suffer from urinary incontinence after being in a nursing home for a year than at admission," with a correct rate of $55.0 \%$ (Table 2). The mean score for UI knowledge was highest among physicians and lowest among physical therapists (Table 3).

Regarding UI practice behaviors, $93.9 \%$ of participants reported that they informed the physician about a patient's UI, and $61.5 \%$ of participants knew the fluid intake patterns of patients (Table 4). However, there was no relationship between the mean knowledge score and length of work experience in a long-term care hospital. 
Table 4. Differences of urinary incontinence practice behaviors by healthcare providers $(n=756)$

\begin{tabular}{|c|c|c|c|c|}
\hline Practice behaviors & Healthcare providers & Yes & No & P-value \\
\hline Help incontinent patient to use toilets & $\begin{array}{l}\text { Physician } \\
\text { Nurse } \\
\text { Certified caregivers } \\
\text { Physical therapist }\end{array}$ & $\begin{array}{r}61(100) \\
421(97.0) \\
201(94.4) \\
41(87.2)\end{array}$ & $\begin{array}{c}0(0.0) \\
13(3.0) \\
12(5.6) \\
6(12.8)\end{array}$ & 0.003 \\
\hline Informing incontinence to physician & $\begin{array}{l}\text { Physician } \\
\text { Nurse } \\
\text { Certified caregivers } \\
\text { Physical therapist }\end{array}$ & $\begin{array}{r}61(100) \\
414(95.4) \\
196(92.0) \\
39(80.9)\end{array}$ & $\begin{array}{c}0(0.0) \\
20(4.6) \\
17(8.0) \\
9(19.1)\end{array}$ & $<0.001$ \\
\hline Confirmation of incontinence on admission & $\begin{array}{l}\text { Physician } \\
\text { Nurse } \\
\text { Certified caregivers } \\
\text { Physical therapist }\end{array}$ & $\begin{array}{r}38(62.3) \\
374(86.4) \\
180(84.5) \\
33(68.8)\end{array}$ & $\begin{array}{l}23(37.7) \\
59(13.6) \\
33(15.5) \\
15(31.2)\end{array}$ & $<0.001$ \\
\hline Documentation of the drinking time of patients & $\begin{array}{l}\text { Physician } \\
\text { Nurse } \\
\text { Certified caregivers } \\
\text { Physical therapist }\end{array}$ & $\begin{array}{r}41(67.2) \\
309(71.2) \\
135(63.4) \\
31(66.0)\end{array}$ & $\begin{array}{r}20(32.8) \\
125(28.8) \\
78(36.6) \\
16(34.0)\end{array}$ & 0.239 \\
\hline Known patient's fluid intake & $\begin{array}{l}\text { Physician } \\
\text { Nurse } \\
\text { Certified caregivers } \\
\text { Physical therapist }\end{array}$ & $\begin{array}{r}32(52.5) \\
280(64.5) \\
128(60.1) \\
25(53.2)\end{array}$ & $\begin{array}{r}29(47.5) \\
154(35.5) \\
85(39.9) \\
22(46.8)\end{array}$ & 0.150 \\
\hline
\end{tabular}

Values are presented as number (\%).

Each item of total numbers was different because of missing data.

\section{DISCUSSION}

In this study, we assessed the current management status of patients with urologic issues and examined the level of knowledge and practice behaviors regarding UI among Korean healthcare providers in long-term care hospitals. There were three key findings in this study. First, the participants reported that no long-term care hospital had an on-site urologist and that collaboration with another hospital was the most important factor in improving urologic care in this study. Second, the score for UI knowledge was upper intermediate, and the mean score of physicians was highest. Third, practice behaviors of nurses seemed to be better than those of other healthcare providers.

Although urologic health issues including UI are common in long-term care hospitals, the medical interventions for these issues may be insufficient. Only half of participants stated that current urologic management was effective. This is consistent with previous studies performed in other counties [10-12]. Healthcare providers who do not practice a specialty related to urologic care may overlook urologic issues or provide inadequate care, both in long-term care facilities and in family practice. Trained staff and proper medical equipment are essential to provide effective care for patients with urologic health issues including UI [13]. However, long-term care facilities are slow to integrate technology and train medical staff because of cost and lack of skilled personnel [12]. As shown in this study, an efficient system of collaboration with urologists should be developed to improve health outcomes in long-term care facilities.

The participants of the current study answered about $81 \%$ of knowledge questions correctly on average, a level higher than in previous studies $[8,9]$. Prior studies assessed UI knowledge of nurses and nursing assistants in long-term facilities such as nursing homes; therefore, the level of knowledge might have been lower than in our study. Although the overall mean scores for UI knowledge were upper intermediate, knowledge deficiencies were observed for the prevalence and risk factors of UI. In addition, there were no differences in knowledge scores between nurses and certified caregivers who were not health professionals. Almost 50\% of participants in this study reported that nurses were involved in urologic management; therefore, nursing knowledge would influence the quality of UI care. Insufficient knowledge of UI due to lack of training has been shown to influence the decision-making process in UI care [14].

The overall practice behaviors of nurses seemed to be better than those of other healthcare providers. This resulted from a 
discrepancy related to the differences of the mean score for knowledge among different types of healthcare providers. Moreover, practices of participants might be focused on notification and documentation of UI status rather than prevention or treatment of symptoms. A previous study reported that staffs in long-term care facilities are more concerned about documentation, but UI care is often not consistent with current clinical practice guidelines [15]. We suggest that a goal of patient participation and tailored educational programs based on individual patient needs should be developed to improve UI care. A staff training program to improve competency in urologic care including UI should be developed in long-term care hospitals.

This study has some limitations. This study employed a purposive nonrandom sampling method. The findings of this study may have compromised external validity and have limited generalization. Finally, the research results of management status, knowledge, and practice behaviors were measured using selfreporting questionnaires. In addition, questionnaires to assess practice behaviors only included five items. Self-reported data may partially reflect participant clinical practices. However, this research is significant because it is the first study to assess the current management status of patients with urologic issues and to report UI knowledge and practice behaviors among Korean healthcare providers in long-term care hospitals.

Long-term care hospitals focus on palliative and geriatric care [16], where UI is an important and common health problem. The findings of this study present basic information related to UI management competence of healthcare providers in Korean long-term care hospitals. Systematic collaboration between these providers and urologic specialists, enhancing staff competence, and patient-tailored intervention should be recommended to improve quality of care for patients with urologic issues in long-term care hospitals.

\section{REFERENCES}

1. Bettez M1, Tu le M, Carlson K, Corcos J, Gajewski J, Jolivet M, et al. 2012 update: guidelines for adult urinary incontinence collaborative consensus document for the canadian urological association. Can Urol Assoc J 2012;6:354-63.

2. Syan R, Brucker BM. Guideline of guidelines: urinary incontinence. BJU Int 2015 Jun 1 [Epub]. http://dx.doi.org/10.1111/bju.13187.

3. Tennstedt SL, Link CL, Steers WD, McKinlay JB. Prevalence of and risk factors for urine leakage in a racially and ethnically diverse population of adults: the Boston Area Community Health (BACH) Survey. Am J Epidemiol 2008;167:390-9.

4. Kim OB, Yoon H. Prevalence of urinary incontinence, single voided volume, post void residual volume, daytime frequency, and nocturia in women over 40 years. Korean J Adult Nurs 2013;25:679-89.

5. Shin CW, Kim SD, Cho WY. The prevalence and management of urinary incontinence in elderly patients at sanatorium in Busan area. Korean J Urol 2009;50:450-6.

6. Coyne KS, Sexton CC, Irwin DE, Kopp ZS, Kelleher CJ, Milsom I. The impact of overactive bladder, incontinence and other lower urinary tract symptoms on quality of life, work productivity, sexuality and emotional well-being in men and women: results from the EPIC study. BJU Int 2008;101:1388-95.

7. Park WH. Urinary Incontinence and physician's attitude. J Korean Med Sci 2013;28:1559-60.

8. Saxer S, de Bie RA, Dassen T, Halfens RJ. Nurses' knowledge and practice about urinary incontinence in nursing home care. Nurse Educ Today 2008;28:926-34.

9. Lin SY, Wang RH, Lin CC, Chiang HY. Competence to provide urinary incontinence care in Taiwan's nursing homes: perceptions of nurses and nurse assistants. J Wound Ostomy Continence Nurs 2012;39:187-93.

10. Nguyen K, Hunter KF, Wagg A. Knowledge and understanding of urinary incontinence: survey of family practitioners in northern Alberta. Can Fam Physician 2013;59:e330-7.

11. Swanson JG, Skelly J, Hutchison B, Kaczorowski J. Urinary incontinence in Canada. National survey of family physicians' knowledge, attitudes, and practices. Can Fam Physician 2002;48:86-92.

12. Ehlman K, Wilson A, Dugger R, Eggleston B, Coudret N, Mathis S. Nursing home staff members' attitudes and knowledge about urinary incontinence: the impact of technology and training. Urol Nurs 2012;32:205-13.

13. Singh DA. Effective management of long term care facilities. 2nd ed. Sudbury (MA): Jones \& Bartlett Learning; 2009.

14. Taunton RL, Swagerty DL, Lasseter JA, Lee RH. Continent or incontinent? That is the question. J Gerontol Nurs 2005;31:36-44.

15. DuBeau CE, Ouslander JG, Palmer MH. Knowledge and attitudes of nursing home staff and surveyors about the revised federal guidance for incontinence care. Gerontologist 2007;47:468-79.

16. Song $\mathrm{H}$. Long-term care hospital systems in developed countries and the implications for Korea. J Korean Geriatr Soc 2012;16:11420 . 